\title{
Emerging glucose-lowering therapies: a guide for cardiologists
}

Gaurav S Gulsin¹, Matthew PM Graham-Brown'1,2, Melanie J Davies³ and Gerry P McCann¹

\section{Keywords}

Type 2 diabetes mellitus; sodium glucose co-transporter-2 inhibitors; glucagon-like peptide- 1 receptor agonists.

\section{Author affiliations}

1. Department of Cardiovascular Sciences, University of Leicester and the Leicester NIHR Biomedical Research Centre, Glenfield Hospital, Groby Road, Leicester, UK.

2. John Walls Renal Unit, University Hospitals of Leicester NHS Trust, Leicester, UK.

3. Diabetes Research Centre, University of Leicester and the Leicester NIHR Biomedical Research Centre, Leicester General Hospital, Gwendolen Road, Leicester, UK.

Correspondence to: Professor Gerry P McCann, Department of Cardiovascular Sciences, University of Leicester and the Leicester NIHR Biomedical Research Centre, Glenfield Hospital, Groby Road, Leicester, UK. Email: gpm12@leicester.ac.uk. Tel: +44 (0)116 2583038.

Word count: 2,623 


\begin{abstract}
In recent large-scale cardiovascular outcomes trials, two new classes of glucose-lowering medications - sodium glucose co-transporter 2 inhibitors (SGLT2i) and glucagon like peptide-1 receptor agonists (GLP-1RAs) demonstrated cardiovascular benefits in adults with type 2 diabetes mellitus (T2DM). These findings have prompted growing optimism amongst clinicians regarding the potential for these agents to reduce the burden of cardiovascular disease in people with T2DM. GLP-1RAs and SGLT2i are now advocated as second-line agents in European and U.S. guidelines for management of both hyperglycaemia and for primary prevention of cardiovascular disease in people with T2DM. Given the high prevalence of T2DM in patients with cardiovascular disease, cardiologists will increasingly encounter these agents in routine clinical practice. In this review, we summarise evidence from cardiovascular outcomes trials of GLP-1RAs and SGLT2i, give practical advice on prescribing, and detail safety considerations associated with their use. We also highlight areas where further work is needed, giving details on active clinical trials. The review aims to familiarise cardiologists with these emerging treatments, which will be increasingly encountered in clinical practice, given the expanding representation of T2DM in patients with cardiovascular disease. Whether these drugs will be initiated by cardiologists remains to be determined.
\end{abstract}




\section{Abbreviations}

ASCVD - atherosclerotic cardiovascular disease

$\mathrm{CV}$ - cardiovascular

CVOT - cardiovascular outcome trial

eGFR - estimated glomerular filtration rate

GLP-1RA - glucagon-like peptide-1 receptor agonist

HFrEF - heart failure with reduced ejection fraction

HFpEF - heart failure with preserved ejection fraction

LDL - low-density lipoprotein

MACE - major adverse cardiovascular events

SGLT2i - sodium glucose co-transporter 2 inhibitors

T2DM - type 2 diabetes mellitus 


\section{Glucagon like peptide-1 receptor agonists}

In 2008 the U.S. Food and Drug Administration, responding to concerns regarding the increased cardiovascular (CV) risk associated with the use of thiazoledinediones (specifically rosiglitazone) ${ }^{1}$, mandated that all new glucose-lowering therapies for type 2 diabetes mellitus (T2DM) be subjected to long-term CV outcomes trials (CVOTs) to demonstrate their safety². The European Medicines Agency later stipulated similar requirements ${ }^{3}$. In the 11 years since these guidance were issued, 17 CVOTs of three classes of glucose-lowering medications (dipeptidyl peptidase 4 inhibitors, glucagon-like peptide-1 receptor agonists (GLP-1RAs), and sodium glucose cotransporter-2 inhibitors (SGLT2i)) have reported. All successfully demonstrated non-inferiority with respect to CV safety profiles compared to placebo. While the CV safety of dipeptidyl peptidase 4 inhibitors is well established, no overall benefit on major adverse cardiovascular events (MACE) is observed with this class of drugs. However, promising CV benefits were observed in several trials of GLP-1RAs and SGLT2i, likely independent of their glucose-lowering effects. This has prompted growing optimism amongst clinicians regarding the potential for these agents to reduce the burden of CV disease in people with T2DM. The use of GLP-1RAs and SGLT2i are now advocated as second-line agents in European and U.S. diabetes guidance for management of hyperglycaemia in people with T2DM4 and in joint American College of Cardiology/American Heart Association primary prevention of CV disease guidelines 5 . Given the high prevalence of T2DM in patients with CV disease, cardiologists will increasingly encounter these agents in routine clinical practice. Furthermore, the CV specialist may even be encouraged to initiate these drugs in patients who may benefit from their use few cardiologists will be comfortable in this regard. In this review, we summarise existing data from CVOTs of GLP-1RAs and SGLT2i, give practical advice on prescribing, and detail safety considerations for clinicians associated with these agents for the general cardiologist.

GLP-1RAs exert their effects by suppressing appetite, glucagon secretion, gastric emptying, and by stimulating the release of insulin' ${ }^{6}$. These actions lead to reductions in plasma glucose and weight loss (which is more pronounced in higher levels of obesity) (Figure 1). Several recent, but not all, CVOTs of GLP-1RAs have shown exciting results with improved glycaemic control as well as reductions in MACE in people with T2DM4(Table 
1). Notably, the benefits of GLP-1RAs appear to be on the on the prevention of atherosclerotic cardiovascular disease (ASCVD) events (myocardial infarction and stroke), with no observed improvements on heart failure hospitalisations. The first of these trials to demonstrate CV benefit was the LEADER trial, in which people with T2DM and high cardiovascular risk treated with liraglutide had lower rates of cardiovascular death compared to those treated with placebo ${ }^{7}$. Subsequently, in high risk T2DM patients, cardiovascular event rates (death, non-fatal myocardial infarction and non-fatal stroke) have been found to be significantly lower with semaglutide $^{8}$, albiglutide ${ }^{9}$ and dulaglutide ${ }^{10}$. Three randomised trials of GLP-1RAs versus placebo, however, did not demonstrate CV benefit. The ELIXA trial of lixisenatide versus placebo achieved non-inferiority but not superiority for the primary composite endpoint of cardiovascular death, myocardial infarction, stroke, or hospitalization for unstable angina. However, this was in patients within 180 days of an acute coronary event ${ }^{11}$. In the EXSCEL trial, there was no overall cardiovascular risk benefit with exenatide, although this study included patients with or without a prior history of CV disease ${ }^{12}$. Lastly, the recent PIONEER 6 trial of oral Semaglutide (the first oral GLP-1RA) met the primary endpoint of non-inferiority versus placebo but did not achieve superiority, although rates of CV death were reduced. However, the follow-up duration in this trial was shorter (1.3 years) compared to the other GLP-1RA CVOTs ${ }^{13}$.

\section{Practical considerations for prescribing}

17 Joint European and U.S. guidelines now suggest GLP-1RAs be recommended as part of the management of hyperglycaemia ( $\mathrm{HbA} 1 \mathrm{c} \geq 7 \%$ or $\geq 53 \mathrm{mmol} / \mathrm{mol}$ ) in people with $\mathrm{T} 2 \mathrm{DM}$, especially in those with established or at high risk of $\mathrm{ASCVD}^{4}$. Lifestyle advice encouraging weight loss and increased physical activity and metformin therapy remain first-line management strategies. This is primarily because in all CVOTs of GLP-1RAs (and indeed SGLT2i), the vast majority of patients were on a background of metformin therapy. All but one of the GLP-1RAs are administered via subcutaneous injection and oral semaglutide has not yet been licensed, although applications for approval are pending14 ${ }^{15}$. Patient factors such as baseline weight, blood pressure, glycated haemoglobin level, renal function and dosing preference are all key considerations (Figure 2). In addition to lowering glycated haemoglobin levels, GLP-1RAs have consistently been shown to induce weight loss (although this varies across the GLP-1RA class), with greater effects seen in those with higher baseline weight, lower blood pressure, and cause small increases in heart rate (Table 2). Approximately one quarter of subjects in the GLP-1RA CVOTs had moderate renal impairment (estimated glomerular filtration rate, eGFR, 
demonstrated reduced rates of new or worsening nephropathy with GLP-1RA treatment compared to placebo $^{7}$ 817 . No dose adjustment of most GLP-1RA is necessary in patients with mild, moderate or severe renal impairment (Table 2), but in patients with end-stage renal disease GLP-1RAs are not recommended due to limited available trial data ${ }^{17}$. Therefore, GLP-1RAs are a good choice for management of hyperglycaemia in T2DM patients with or at risk of ASCVD, with the common accompanying comorbidities of obesity and hypertension, and may be used in those with moderate and even severe renal impairment (selected agents may be prescribed in individuals with eGFR as low as $15 \mathrm{~mL} / \mathrm{min} / 1.73 \mathrm{~m}^{2}$ )(Figure 2).

\section{Risks and side effects}

The commonest side effects of GLP-1RAs are gastrointestinal symptoms, particularly nausea, vomiting and diarrhoea ${ }^{19}$. Rare instances of acute pancreatitis and gallstones have been reported, although these could not convincingly be attributed to GLP-1RA treatment in a recent meta-analysis ${ }^{20}$ and may instead be related to hypertriglyceridaemia and obesity which commonly co-exist in people with T2DM ${ }^{21}$. Starting GLP-1RAs at a low dose with gradual dose increases may lower the occurrence of gastrointestinal side effects, particularly nausea. Rates of hypoglycaemia varied from 1.5 to 4-fold in CVOTs with GLP-1RA use versus placebo, although there is no statistically significant difference in the incidence of hypoglycaemic events among the different GLP1RAs ${ }^{16}$. Importantly, GLP-1RA use is associated with modest increases in heart rate ${ }^{16}$. The mechanism by which this occurs is unclear, although may be related to increased sympathetic nervous system activity or direct sinoatrial node stimulation ${ }^{22}$. This may explain why GLP-1RA treatment did not result in lower rates of heart failure hospitalisation CVOTs. Indeed, two trials have assessed GLP-1RA treatment in heart failure with reduced ejection fraction (HFrEF) patients. In the LIVE trial (Effect of Liraglutide, a Glucagon-like Peptide-1 Analogue, on Left Ventricular Function in Stable Chronic Heart Failure Patients With and Without Diabetes), treatment with Liraglutide was associated with more adverse CV events compared to placebo, although the sample size in this study was small $(n=241)$ and overall event rates were low ${ }^{23}$. Similarly, the FIGHT trial (Functional Impact of GLP-1 for Heart Failure Treatment) showed a trend towards harm with GLP-1RA treatment in recently hospitalized (within 14 days of an acute heart failure admission) patients with $\operatorname{HFrEF}(\mathrm{n}=300)^{24}$. On available evidence, we therefore recommend caution when using GLP-1RAs in patients with T2DM and HFrEF, and give preference to SGLT2i in these individuals. This is consistent with American Diabetes Association/European Association for the Study of Diabetes consensus guidelines4. 


\section{Trial data}

SGLT2i prevent reabsorption of glucose in the proximal convoluted tubule promoting urinary glucose excretion and thereby lowering blood glucose levels. Secondary effects include weight loss, a modest diuretic effect and blood pressure reduction $^{25}$ (Figure 1). Three major CVOTs of SGLT2i have been completed (Table 3) ${ }^{26-28}$. In the first two of these - the EMPA-REG OUTCOME27 and CANVAS ${ }^{28}$ studies - there was a relative risk reduction in MACE and hospitalisation for heart failure ( $\sim 33 \%$ reduction) in patients with T2DM with established or at high-risk of cardiovascular disease. More recently, in the largest of the SGLT2i trials with the longest follow up duration - DECLARE-TIMI 58 study of the SGLT2i Dapagliflozin versus placebo - reduced rates of hospitalization for heart failure were also observed in lower risk subjects with T2DM26. In a secondary analysis of patients from DECLARE TIMI 58 stratified according to left ventricular ejection fraction at baseline ( $\mathrm{n}=671$ with HFrEF, n=1316 with heart failure with preserved, HFpEF, or unknown ejection fraction, and n=15173 with no history of heart failure), the greatest reductions in CV mortality and heart failure hospitalisations were observed in patients with HFrEF (HR 0.62, 95\% CI 0.45-0.86) ${ }^{29}$. This suggests that SGLT2i are of added benefit in patients with T2DM and HFrEF. However, it is important that the results of these studies be viewed with a degree of caution. Heart failure risk reduction was not the primary endpoint in any of the studies and was based on investigator-reported heart failure events rather than objective measures (such as echocardiography or measurement of B-type natriuretic peptide levels). Several trials are now underway to specifically address the effects of SGLT2i in patients with HFrEF (DAPA-HF30 and EMPEROR-Reduced (ClinicalTrials.gov Identifier: NCT03057977), of Dapagliflozin and Empagliflozin, respectively) and HFpEF (EMPEROR-Preserved, ClinicalTrials.gov Identifier: NCT03057951) in people both with and without T2DM.

In addition to CV benefits, several trials have shown improved renal outcomes with SGLT2i, in patients with and without established renal disease. In a post hoc analysis of the EMPA-REG OUTCOME trial, lower rates of new or worsening nephropathy (HR $0.61,95 \%$ CI $0.53-0.70, p<0.001$ ) and the renal composite outcome (doubling of the serum creatinine level, initiation of renal-replacement therapy, or death from renal disease) (HR 0.54, 95\% CI $0.50-0.75, \mathrm{p}<0.001$ ) occurred in the empagliflozin arm versus placebo ${ }^{31}$. Similarly in the CANVAS trial, fewer patients randomized to canagliflozin experienced the renal composite outcome (reduction in eGFR, end-stage renal disease, or death from renal disease) (HR 0.60, 95\% CI 0.47-0.77) versus placebo ${ }^{28}$. 
1 More recently, the CREDENCE trial (Canagliflozin and Renal Endpoints in Diabetes with Established

2 Nephropathy Clinical Evaluation) showed favourable renal outcomes in patients (n=4401) with T2DM and

3 albuminuric chronic kidney disease (eGFr 30 to $<90 \mathrm{ml} / \mathrm{min} / 1.73 \mathrm{~m}^{2}$ ) randomized to Canagliflozin $100 \mathrm{mg}$ daily

4 versus placebo (renal composite outcome (end-stage renal disease, doubling of creatinine level, or death from

5 renal causes) HR 0.66; 95\% CI 0.53-0.81, p<0.001)32. Similar trials planned with Dapagliflozin (Dapa-CKD,

6 ClinicalTrials.gov Identifier: NCT03036150) and Empagliflozin (EMPA-KIDNEY, ClinicalTrials.gov Identifier:

7 NCT03594110). These data suggest that SGLT2i are safe and effective agents for improving clinical outcomes in

8 high-risk renal populations, who frequently suffer concomitant T2DM and heart failure but the current trial

9 evidence has been limited to patients with estimated glomerular filtration rates (eGFR) $>30 \mathrm{ml} / \mathrm{min} / 1.73 \mathrm{~m}^{2}$.

\section{Practical considerations for prescribing}

The joint European and U.S. guidelines recommend SGLT2i as second-line agents in people with T2DM, after metformin and lifestyle management, preferring these over GLP-1RAs in patients with (or at risk of) heart failure or chronic kidney disease ${ }^{4}$. Advantages of prescribing SGLT2i are their oral administration route, modest blood pressure and weight lowering effects, and that they do not generally cause hypoglycaemia (Table 4). Despite showing promise in reducing the progression of chronic kidney disease, the glucose-lowering effects of SGLT2i diminish in patients with renal dysfunction ${ }^{33}$. Therefore SGLT2i may not be suitable for those patients with renal impairment and very poor glycaemic control, where instead GLP-1RAs may achieve superior reductions in glycated haemoglobin. Furthermore, transient reductions in eGFR rate are observed following initiation of SGLT2i and close monitoring of renal function is advised in patients recent commenced on these drugs ${ }^{33}$. In any case, SGLT2i are contraindicated in patients with eGFR $<30 \mathrm{~mL} / \mathrm{min} / 1.73 \mathrm{~m}^{2}$ and dosing adjustments may be necessary in patients with eGFR $<60 \mathrm{~mL} / \mathrm{min} / 1.73 \mathrm{~m}^{2}$ (Table 4). However, the promising renoprotective effects of SGLT2i, together with their positive effects on weight loss and blood pressure reduction suggest that these agents may have play major role in patients with chronic kidney disease in the future. Lastly, small increases in low-density lipoprotein (LDL) cholesterol levels and haematocrit are associated with SGLT2i use ${ }^{34}$. Increased LDL cholesterol levels are likely due to reduced clearance ${ }^{36}$. Haematocrit elevation (which are likely to benefit patients with heart failure) may not be solely the result of volume depletion and could also be due to increased erythropoietin levels ${ }^{35}$. Neither elevated LDL or haematocrit levels translated into increased ASCVD events in clinical trials, and monitoring of LDL cholesterol or haematocrit specifically for patients on SGLT2i is probably not warranted. 
2 The commonest side effects associated with SGLT2i are an increased risk of urinary tract and genital 3 infections ${ }^{37}$. The diuretic effect of SGLT2i may lead to thirst, polyuria and ultimately volume depletion, which is 4 accompanied by orthostatic hypotension in some cases. Risk factors for volume depletion include age $>75$ 5 years, eGFR $<60 \mathrm{ml} / \mathrm{min} / 1.73 \mathrm{~m}^{2}$ and concomitant loop diuretic use ${ }^{38}$. This is especially relevant in heart failure 6 patients, who are often older, have impaired renal function, and may be taking several drugs with diuretic 7 effects (such as angiotensin/neprilysin inhibitors, loop and/or thiazide diuretics, and aldosterone antagonists). 8 We advise careful monitoring of these patients when initiating SGLT2i to avoid volume depletion and 9 worsening of renal function and the dose of existing diuretics may be reduced. The results of the, Dapa-HF, 10 EMPEROR-Reduced and EMPEROR-Preserved trials will hopefully shed light on the impact of SGLT2i in 11 patients with heart failure taking multiple guideline-directed medications.

12 Rarer observed complications of SGLT2i include an increased risk of limb amputation (incidence rate 2.7 13 events per 1000 person years), risk of fracture (incidence rate 15.4 events per 1000 person years), euglycaemic 14 diabetic ketoacidosis (incidence rate 1.3 events per 1000 person years) ${ }^{39}{ }^{40}$. The rapid increase in urinary 15 glucose excretion with SGLT2i results in a reduction in plasma insulin levels and corresponding increase in 16 glucagon secretion. In euglycaemic diabetic ketoacidosis, this shift in hormone balance promotes increased 17 gluconeogenesis by the liver and increased lipolysis, resulting in ketogenesis and then ketoacidosis ${ }^{39}$. Normal or mildly elevated blood glucose levels can make the diagnosis challenging, and clinicians should be alert to the possibility of this complication in patients taking SGLT2i. The risk of euglygcaemic diabetic ketoacidosis is increased in patients taking insulin when doses are reduced suddenly, in patients with concurrent illness 21 (where stopping SGLT2i is advised when the patient is unable to eat or drink, or has persistent vomiting or diarrhoea), and in those on low carbohydrate diets ${ }^{4}$. The increased risk of fractures and lower limb amputations were primarily observed in the CANVAS trial28. Canagliflozin has been shown to cause a decline in bone mineral density, which explains the risk of fractures associated with the drug ${ }^{41}$. Very rarely necrotising fasciitis of the genitalia or perineum has been reported but the very low incidence is likely to be outweighed by the dramatic reductions in heart failure ${ }^{42}$. 


\section{Conclusions}

2 The emergence of two classes of glucose-lowering therapies - GLP-1RAs and SGLT2i- with demonstrable 3 benefits on $\mathrm{CV}$ outcomes in people with T2DM, has given cause for optimism for clinicians treating this 4 expanding group of patients. Whilst lifestyle management and metformin remain the mainstay of treatment of 5 hyperglycaemia in people with T2DM, these newer agents are now recommended to be part of glycaemic 6 management in patients with ASCVD, chronic kidney disease and heart failure, and will increasingly be 7 encountered by cardiologists. There remain questions about the role of SGLT2i in patients with HFrEF and 8 HFpEF, which will hopefully be answered in upcoming clinical trials. Regardless, SGLT2i and GLP-1RAs are 9 increasingly being recognised as both glucose-lowering drugs with cardiovascular benefit and cardiovascular 10 drugs with glucose-lowering effects. In the recent 2019 joint American College of Cardiology/American Heart 11 Association guidance on the primary prevention of cardiovascular disease, both classes of drug are 12 recommended for adults with T2DM with risk factors for ASCVD as second-line agents ${ }^{5}$. Cardiologists should 13 therefore become accustomed to the trial data evidencing the CV benefits of SGLT2i and GLP-1RAs, the 14 practical aspects of prescribing these drugs, and the risks associated with their use. 


\section{Footnotes}

\section{Author contributions}

GSG and GPM conceived the idea for the review. GSG and MPMGB drafted the manuscript, which was critically reviewed by GPM and MJD. All authors approved the final submission.

\section{Funding}

GSG is funded through a British Heart Foundation Clinical Research Training Fellowship (CRTF 32190, GS Gulsin). GPM is funded through a National Institute for Health Research (NIHR) Research Professorship (RP2017-08-ST2-007, GP McCann). All authors receive support from the NIHR Leicester Biomedical Research Centre and the NIHR Leicester Clinical Research Facility

\section{Competing interests}

None.

\section{Provenance and peer review}

Not commissioned: externally peer-reviewed.

\section{Permissions}

The Corresponding Author has the right to grant on behalf of all authors and does grant on behalf of all authors, an exclusive licence (or non exclusive for government employees) on a worldwide basis to the BMJ Publishing Group Ltd and its Licensees to permit this article (if accepted) to be published in HEART editions and any other BMJPGL products to exploit all subsidiary rights. 


\section{References}

1. Nissen SE, Wolski K. Effect of rosiglitazone on the risk of myocardial infarction and death from cardiovascular causes. N Engl J Med 2007;356(24):2457-71.

2. U.S. Food and Drug Administration. Diabetes Mellitus - Evaluating Cardiovascular Risk in New Antidiabetic Therapies to Treat Type 2 Diabetes 2008 [Available from: https://www.fda.gov/regulatoryinformation/search-fda-guidance-documents/diabetes-mellitus-evaluating-cardiovascular-risk-newantidiabetic-therapies-treat-type-2-diabetes.

3. European Medicines Agency. Guideline on clinical investigation of medicinal products in the treatment or prevention of diabetes mellitus. European Medicines Agency, 2012.

4. Davies MJ, D'Alessio DA, Fradkin J, et al. Management of hyperglycaemia in type 2 diabetes, 2018. A consensus report by the American Diabetes Association (ADA) and the European Association for the Study of Diabetes (EASD). Diabetologia 2018.

5. Arnett DK, Blumenthal RS, Albert MA, et al. 2019 ACC/AHA Guideline on the Primary Prevention of Cardiovascular Disease: Executive Summary: A Report of the American College of Cardiology/American Heart Association Task Force on Clinical Practice Guidelines. J Am Coll Cardiol 2019.

6. Nauck MA, Heimesaat MM, Behle K, et al. Effects of Glucagon-Like Peptide 1 on Counterregulatory Hormone Responses, Cognitive Functions, and Insulin Secretion during Hyperinsulinemic, Stepped Hypoglycemic Clamp Experiments in Healthy Volunteers. The Journal of Clinical Endocrinology \& Metabolism 2002;87(3):1239-46.

7. Marso SP, Daniels GH, Brown-Frandsen K, et al. Liraglutide and Cardiovascular Outcomes in Type 2 Diabetes. N Engl J Med 2016;375(4):311-22.

8. Marso SP, Bain SC, Consoli A, et al. Semaglutide and Cardiovascular Outcomes in Patients with Type 2 Diabetes. N Engl J Med 2016;375(19):1834-44.

9. Hernandez AF, Green JB, Janmohamed S, et al. Albiglutide and cardiovascular outcomes in patients with type 2 diabetes and cardiovascular disease (Harmony Outcomes): a double-blind, randomised placebocontrolled trial. Lancet 2018.

10. Gerstein HC, Colhoun HM, Dagenais GR, et al. Dulaglutide and cardiovascular outcomes in type 2 diabetes (REWIND): a double-blind, randomised placebo-controlled trial. Lancet 2019.

11. Pfeffer MA, Claggett B, Diaz R, et al. Lixisenatide in Patients with Type 2 Diabetes and Acute Coronary Syndrome. N Engl J Med 2015;373(23):2247-57.

12. Holman RR, Bethel MA, Mentz RJ, et al. Effects of Once-Weekly Exenatide on Cardiovascular Outcomes in Type 2 Diabetes. N Engl J Med 2017;377(13):1228-39.

13. Husain M, Birkenfeld AL, Donsmark M, et al. Oral Semaglutide and Cardiovascular Outcomes in Patients with Type 2 Diabetes. N Engl J Med 2019.

14. European Pharmaceutical Review. Application to EMA filed for the approval of oral semaglutide 2019 [Available from: https://www.europeanpharmaceuticalreview.com/news/86836/application-toeuropean-medicines-agency-filed-for-the-approval-of-oral-semaglutide/.

15. Caffrey M, DiGrande S. Novo Nordisk Seeks Oral Semaglutide Approval, CV Indications on New Drug and Injectable: AJMC; 2019 [Available from: https://www.ajmc.com/newsroom/novo-nordisk-seeks-oralsemaglutide-approval-cv-indications-on-new-drug-and-injectable-.

16. Zaccardi F, Htike ZZ, Webb DR, et al. Benefits and Harms of Once-Weekly Glucagon-like Peptide-1 Receptor Agonist Treatments: A Systematic Review and Network Meta-analysis. Ann Intern Med 2016;164(2):102-13.

17. Gerstein HC, Colhoun HM, Dagenais GR, et al. Dulaglutide and renal outcomes in type 2 diabetes: an exploratory analysis of the REWIND randomised, placebo-controlled trial. Lancet 2019.

18. European Medicines Agency. Annex 1: Summary of Product Characteristics for Victoza 2014 [Available from: https://www.ema.europa.eu/en/documents/product-information/victoza-epar-productinformation en.pdf.

19. Sun F, Chai S, Yu K, et al. Gastrointestinal adverse events of glucagon-like peptide-1 receptor agonists in patients with type 2 diabetes: a systematic review and network meta-analysis. Diabetes Technol Ther 2015;17(1):35-42.

20. Storgaard H, Cold F, Gluud LL, et al. Glucagon-like peptide-1 receptor agonists and risk of acute pancreatitis in patients with type 2 diabetes. Diabetes Obes Metab 2017;19(6):906-08.

21. Drucker DJ, Sherman SI, Gorelick FS, et al. Incretin-based therapies for the treatment of type 2 diabetes: evaluation of the risks and benefits. Diabetes Care 2010;33(2):428-33. 
22. Nakatani Y, Kawabe A, Matsumura M, et al. Effects of GLP-1 Receptor Agonists on Heart Rate and the Autonomic Nervous System Using Holter Electrocardiography and Power Spectrum Analysis of Heart Rate Variability. Diabetes Care 2016;39(2):e22-3.

23. Jorsal A, Kistorp C, Holmager $P$, et al. Effect of liraglutide, a glucagon-like peptide- 1 analogue, on left ventricular function in stable chronic heart failure patients with and without diabetes (LIVE)-a multicentre, double-blind, randomised, placebo-controlled trial. Eur J Heart Fail 2017;19(1):69-77.

24. Margulies KB, Hernandez AF, Redfield MM, et al. Effects of Liraglutide on Clinical Stability Among Patients With Advanced Heart Failure and Reduced Ejection Fraction: A Randomized Clinical Trial. JAMA 2016;316(5):500-8.

25. Sattar N, Petrie MC, Zinman B, et al. Novel Diabetes Drugs and the Cardiovascular Specialist. J Am Coll Cardiol 2017;69(21):2646-56.

26. Wiviott SD, Raz I, Bonaca MP, et al. Dapagliflozin and Cardiovascular Outcomes in Type 2 Diabetes. N Engl J Med 2018.

27. Zinman B, Wanner C, Lachin JM, et al. Empagliflozin, Cardiovascular Outcomes, and Mortality in Type 2 Diabetes. N Engl J Med 2015;373(22):2117-28.

28. Neal B, Perkovic V, Mahaffey KW, et al. Canagliflozin and Cardiovascular and Renal Events in Type 2 Diabetes. N Engl J Med 2017;377(7):644-57.

29. Kato ET, Silverman MG, Mosenzon O, et al. Effect of Dapagliflozin on Heart Failure and Mortality in Type 2 Diabetes Mellitus. Circulation 2019;139(22):2528-36.

30. McMurray JJV, DeMets DL, Inzucchi SE, et al. A trial to evaluate the effect of the sodium-glucose cotransporter 2 inhibitor dapagliflozin on morbidity and mortality in patients with heart failure and reduced left ventricular ejection fraction (DAPA-HF). Eur J Heart Fail 2019;21(5):665-75.

31. Wanner C, Inzucchi SE, Lachin JM, et al. Empagliflozin and Progression of Kidney Disease in Type 2 Diabetes. N Engl J Med 2016;375(4):323-34.

32. Perkovic V, Jardine MJ, Neal B, et al. Canagliflozin and Renal Outcomes in Type 2 Diabetes and Nephropathy. N Engl J Med 2019;380(24):2295-306.

33. Kelly MS, Lewis J, Huntsberry AM, et al. Efficacy and renal outcomes of SGLT2 inhibitors in patients with type 2 diabetes and chronic kidney disease. Postgrad Med 2019;131(1):31-42.

34. Zaccardi F, Webb DR, Htike ZZ, et al. Efficacy and safety of sodium-glucose co-transporter-2 inhibitors in type 2 diabetes mellitus: systematic review and network meta-analysis. Diabetes Obes Metab 2016;18(8):783-94.

35. Sano M, Goto S. Possible Mechanism of Hematocrit Elevation by Sodium Glucose Cotransporter 2 Inhibitors and Associated Beneficial Renal and Cardiovascular Effects. Circulation 2019;139(17):1985-87.

36. Basu D, Huggins LA, Scerbo D, et al. Mechanism of Increased LDL (Low-Density Lipoprotein) and Decreased Triglycerides With SGLT2 (Sodium-Glucose Cotransporter 2) Inhibition. Arterioscler Thromb Vasc Biol 2018;38(9):2207-16.

37. Monami M, Nardini C, Mannucci E. Efficacy and safety of sodium glucose co-transport-2 inhibitors in type 2 diabetes: a meta-analysis of randomized clinical trials. Diabetes Obes Metab 2014;16(5):457-66.

38. Desouza CV, Gupta N, Patel A. Cardiometabolic Effects of a New Class of Antidiabetic Agents. Clin Ther 2015;37(6):1178-94.

39. Hsia DS, Grove 0, Cefalu WT. An update on sodium-glucose co-transporter-2 inhibitors for the treatment of diabetes mellitus. Curr Opin Endocrinol Diabetes Obes 2017;24(1):73-79.

40. Ueda P, Svanstrom H, Melbye M, et al. Sodium glucose cotransporter 2 inhibitors and risk of serious adverse events: nationwide register based cohort study. BMJ 2018;363:k4365.

41. Bilezikian JP, Watts NB, Usiskin K, et al. Evaluation of Bone Mineral Density and Bone Biomarkers in Patients With Type 2 Diabetes Treated With Canagliflozin. J Clin Endocrinol Metab 2016;101(1):44-51.

42. Matthews DR, Li Q, Perkovic V, et al. Effects of canagliflozin on amputation risk in type 2 diabetes: the CANVAS Program. Diabetologia 2019;62(6):926-38.

43. Andreadis P, Karagiannis T, Malandris K, et al. Semaglutide for type 2 diabetes mellitus: A systematic review and meta-analysis. Diabetes Obes Metab 2018;20(9):2255-63.

44. Kapitza C, Forst T, Coester HV, et al. Pharmacodynamic characteristics of lixisenatide once daily versus liraglutide once daily in patients with type 2 diabetes insufficiently controlled on metformin. Diabetes Obes Metab 2013;15(7):642-9.

45. Care D. Standards of Medical Care in Diabetes - 2018. In: American Diabetes A, ed. 1 ed, 2018.

46. Abbasi J. Oral GLP-1 Analog for Type 2 Diabetes on the Horizon. JAMA 2018;320(6):539.

47. Mazidi M, Rezaie P, Gao HK, et al. Effect of Sodium-Glucose Cotransport-2 Inhibitors on Blood Pressure in People With Type 2 Diabetes Mellitus: A Systematic Review and Meta-Analysis of 43 Randomized Control Trials With 22528 Patients. J Am Heart Assoc 2017;6(6). 
Tables

\begin{tabular}{|c|c|c|c|c|c|c|}
\hline Study & Agent & $\begin{array}{l}\text { Sample size } \\
\text { (n) }\end{array}$ & $\begin{array}{l}\text { Key inclusion } \\
\text { criteria }\end{array}$ & $\begin{array}{l}\text { Average } \\
\text { age (y) }\end{array}$ & $\begin{array}{l}\text { Follow up } \\
\text { duration }(y)\end{array}$ & Key findings \\
\hline LEADER $^{7}$ & Liraglutide & $\begin{array}{l}\text { Total: } 9340 \\
\text { Drug: } 4668 \\
\text { Placebo: } 4672\end{array}$ & $\begin{array}{l}\text { T2DM and CVD, } \\
\text { A1c } \geq 7.0 \%\end{array}$ & 64 & 3.8 & $\begin{array}{l}\text { Primary outcome, HR } 0.87 \text { ( } 95 \% \text { CI } 0.78-0.97) \text {; MI, HR } \\
0.88 \text { ( } 95 \% \text { CI } 0.75-1.03) ; \text { stroke, HR } 0.89 \text { ( } 95 \% \text { CI } 0.72- \\
1.11) \text {; CV death, HR 0.78 ( } 95 \% \text { CI } 0.66-0.93) ; \mathrm{HF} \\
\text { hospitalisation, HR } 0.87 \text { ( } 95 \% \text { CI } 0.77-1.61) \text {. }\end{array}$ \\
\hline SUSTAIN-6 ${ }^{8}$ & Semaglutide & $\begin{array}{l}\text { Total: } 3297 \\
\text { Drug: } 1648 \\
\text { Placebo: } 1649\end{array}$ & $\begin{array}{l}\text { T2DM and CVD, } \\
\mathrm{A} 1 \mathrm{c} \geq 7.0 \%\end{array}$ & 65 & 2.1 & $\begin{array}{l}\text { Primary outcome, HR } 0.74 \text { ( } 95 \% \text { CI } 0.58-0.95) \text {; MI, HR } \\
0.74 \text { ( } 95 \% \text { CI } 0.51-1.08) \text {; stroke, HR } 0.61(95 \% \text { CI } 0.38- \\
0.99) ; \text { CV death, HR 0.98 ( } 95 \% \text { CI } 0.65-1.48) ; \text { HF } \\
\text { hospitalisation, HR } 1.11 \text { ( } 95 \% \text { CI } 0.75-1.23) \text {. }\end{array}$ \\
\hline EXSCEL $^{12}$ & Exenatide & $\begin{array}{l}\text { Total: } 14752 \\
\text { Drug: } 7356 \\
\text { Placebo: } 7396\end{array}$ & $\begin{array}{l}\text { T2DM, } 70 \% \text { with } \\
\text { CVD and } 30 \% \\
\text { without, A1c } 6.5- \\
10 \%\end{array}$ & 62 & 3.2 & $\begin{array}{l}\text { Primary outcome, HR } 0.91 \text { ( } 95 \% \text { CI } 0.83-1.00) \text {; MI, HR } \\
0.97 \text { ( } 95 \% \text { CI } 0.85-1.10) \text {; stroke, HR } 0.85(95 \% \text { CI } 0.70- \\
1.03) \text {; CV death, HR } 0.88 \text { ( } 95 \% \text { CI } 0.0 .76-1.02) ; \mathrm{HF} \\
\text { hospitalisation, HR } 0.94(95 \% \text { CI } 0.78-1.13) \text {. }\end{array}$ \\
\hline $\begin{array}{l}\text { HARMONY } \\
\text { OUTCOMES } \\
9\end{array}$ & Albiglutide & $\begin{array}{l}\text { Total: } 9463 \\
\text { Drug: } 4731 \\
\text { Placebo: } 4732\end{array}$ & $\begin{array}{l}\text { T2DM and CVD, } \\
\text { A1c }>7 \%\end{array}$ & 64 & 1.5 & $\begin{array}{l}\text { Primary outcome, HR } 0.78 \text { (95\% CI } 0.68-0.90) \text {; MI, HR } \\
0.75 \text { ( } 95 \% \text { CI } 0.61-0.90) \text {; stroke, HR } 0.86 \text { (95\% CI 0.66- } \\
1.14 \text { ); CV death, HR } 0.93 \text { (95\% CI 0.73-1.19). }\end{array}$ \\
\hline ELIXA $^{11}$ & Lixisenatide & $\begin{array}{l}\text { Total: } 6068 \\
\text { Drug: } 3034 \\
\text { Placebo: } 3034\end{array}$ & $\begin{array}{l}\text { T2DM, ACS } \leq 180 \\
\text { days, A1c } 5.5- \\
11 \%\end{array}$ & 60 & 2.1 & $\begin{array}{l}\text { Primary outcome, HR } 1.02 \text { ( } 95 \% \text { CI } 0.89-1.17) \text {; MI, HR } \\
1.03 \text { ( } 95 \% \text { CI } 0.87-1.22) \text {; stroke, HR } 1.12 \text { ( } 95 \% \text { CI } 0.79- \\
1.58) ; \text { CV death, HR } 0.98 \text { ( } 95 \% \text { CI } 0.78-1.22) ; \text { HF } \\
\text { hospitalisation, HR } 0.96(95 \% \text { CI } 0.75-1.23) \text {. }\end{array}$ \\
\hline $\begin{array}{l}\text { PIONEER- } \\
6^{13}\end{array}$ & $\begin{array}{l}\text { Oral } \\
\text { semaglutide }\end{array}$ & $\begin{array}{l}\text { Total: } 3183 \\
\text { Drug: } 1591 \\
\text { Placebo: } 1592\end{array}$ & T2DM and CVD & 66 & 1.3 & $\begin{array}{l}\text { Primary outcome, HR } 0.79 \text { ( } 95 \% \text { CI } 0.57-1.11) \text {; MI, HR } \\
1.18 \text { ( } 95 \% \text { CI } 0.73-1.90) ; \text { stroke, HR } 0.74(95 \% \text { CI } 0.35- \\
1.57) ; \text { CV death, HR } 0.49 \text { ( } 95 \% \text { CI } 0.27-0.92) ; \text { HF } \\
\text { hospitalisation, HR } 0.86(95 \% \text { CI } 0.48-1.55) \text {. }\end{array}$ \\
\hline REWIND $^{10}$ & Dulaglutide & $\begin{array}{l}\text { Total: } 9901 \\
\text { Drug: } 4949 \\
\text { Placebo: } 4952\end{array}$ & $\begin{array}{l}\text { T2DM, with prior } \\
\text { CVD or CV risk } \\
\text { factors, A1c } \\
\leq 9.5 \%\end{array}$ & 66 & 5.4 & $\begin{array}{l}\text { Primary outcome, HR } 0.88 \text { ( } 95 \% \text { CI } 0.79-0.99) \text {; MI, HR } \\
0.96 \text { ( } 95 \% \text { CI 0.0.79-1.15); stroke, HR } 0.76 \text { ( } 95 \% \text { CI } \\
0.62-0.94) \text {; CV death, HR } 0.91 \text { (95\% CI } 0.78-1.06) ; \mathrm{HF} \\
\text { hospitalisation, HR } 0.93 \text { (95\% CI } 0.77-1.12 \text { ). }\end{array}$ \\
\hline
\end{tabular}

Table 1. Cardiovascular Outcomes Trials of Glucagon Like Receptor-1 Agonists. Abbreviations: T2DM=type 2 diabetes mellitus; $\mathrm{CVD}=$ cardiovascular disease; $\mathrm{HR}=$ hazard ratio; $\mathrm{CI}=$ confidence interval; $\mathrm{MI}=$ myocardial infarction; $\mathrm{ACS}=\mathrm{acute}$ coronary syndrome. 


\begin{tabular}{|c|c|c|c|c|c|c|c|}
\hline Drug & Dose & $\begin{array}{l}\text { Dose } \\
\text { interval }\end{array}$ & HbA1c (\%) & Weight (kg) & $\begin{array}{l}\text { Systolic BP } \\
\text { (mmHg) }\end{array}$ & $\begin{array}{l}\text { Heart rate } \\
\text { (bpm) }\end{array}$ & Renal dosing \\
\hline Liraglutide & $0.6-3 \mathrm{mg}$ & Once daily & $\begin{array}{l}-1.15(-1.27,- \\
1.03)\end{array}$ & $\begin{array}{l}-1.96(-2.67,- \\
1.25)\end{array}$ & $-4.04(-5.19,-2.90)$ & $3.28(2.45,4.11)$ & $\begin{array}{l}\text { No dose } \\
\text { adjustment } \\
\text { required }\end{array}$ \\
\hline Semaglutide & $0.5-1 \mathrm{mg}$ & Weekly & $\begin{array}{l}-1.38(-1.70,- \\
1.05)\end{array}$ & $\begin{array}{l}-4.11(-4.85,- \\
3.37)\end{array}$ & $-3.05(-4.63,-1.47)$ & $3.14(2.38,3.91)$ & $\begin{array}{l}\text { No dose } \\
\text { adjustment } \\
\text { required. }\end{array}$ \\
\hline Exenatide* & $\begin{array}{l}5-10 \mu \mathrm{g} \\
\text { twice daily } \\
\text { or } 2 \mathrm{mg} \\
\text { weekly }\end{array}$ & $\begin{array}{l}\text { Weekly or } \\
\text { daily }\end{array}$ & $\begin{array}{l}-1.08(-1.27,- \\
0.89)\end{array}$ & $\begin{array}{l}-1.49(-2.58,- \\
0.40)\end{array}$ & $-3.64(-5.15,-2.13)$ & $3.25(1.60,4.91)$ & $\begin{array}{l}\text { Avoid if eGFR } \\
<30\end{array}$ \\
\hline Albiglutide & $30-50 \mathrm{mg}$ & Weekly & $\begin{array}{l}-0.94(-1.24,- \\
0.64)\end{array}$ & $\begin{array}{l}-0.41(-2.32- \\
1.50)\end{array}$ & $-3.35(-4.61,-2.10)$ & $1.3(0.9,1.6)$ & $\begin{array}{l}\text { Avoid if eGFR } \\
<15\end{array}$ \\
\hline Lixisenatide & $10-20 \mu \mathrm{g}$ & Once daily & $\begin{array}{l}-0.55(-0.68,- \\
0.42)\end{array}$ & $\begin{array}{l}-0.78(-1.48,- \\
0.09)\end{array}$ & $-2.0(-4.90,0.80)$ & $\begin{array}{l}-0.20(-1.48 \\
1.08)\end{array}$ & $\begin{array}{l}\text { Avoid if eGFR } \\
<15\end{array}$ \\
\hline Dulaglutide & $1.5 \mathrm{mg}$ & Weekly & $\begin{array}{l}-1.21(-1.36,- \\
1.05)\end{array}$ & $\begin{array}{l}-1.57(-2.48,- \\
0.66)\end{array}$ & $-3.43(-4.69,-2.17)$ & $2.59(1.75,3.43)$ & $\begin{array}{l}\text { No dose } \\
\text { adjustment } \\
\text { required }\end{array}$ \\
\hline
\end{tabular}

Table 2. Effects of Glucagon Like Receptor-1 Agonists on Glycated Haemoglobin, Weight, Systolic Blood Pressure and Heart Rate $^{91643-45}$. All agents are administered subcutaneously, with the exception of semaglutide (for which both oral and subcutaneous formulations are available $)^{46}$. All data are presented as mean $\left(95 \%\right.$ confidence interval). ${ }^{*}$ Data on Exenatide pertain to weekly dosing interval. 


\begin{tabular}{|c|c|c|c|c|c|c|}
\hline Study & Agent & $\begin{array}{l}\text { Sample size } \\
\text { (n) }\end{array}$ & $\begin{array}{l}\text { Key inclusion } \\
\text { criteria }\end{array}$ & $\begin{array}{l}\text { Average } \\
\text { age (y) }\end{array}$ & $\begin{array}{l}\text { Follow up } \\
\text { duration }(y)\end{array}$ & Key findings \\
\hline $\begin{array}{l}\text { EMPA-REG } \\
\text { OUTCOME }^{27}\end{array}$ & Empagliflozin & $\begin{array}{l}\text { Total: } 7020 \\
\text { Drug: } 4687 \\
\text { Placebo: } 2333\end{array}$ & $\begin{array}{l}\text { T2DM and CVD, } \\
\text { HbA1c } 7-10 \%\end{array}$ & 63 & 3.1 & $\begin{array}{l}\text { Primary outcome, HR } 0.86 \text { (95\% CI } 0.74-0.99) ; \mathrm{MI}, \mathrm{HR} \\
0.87 \text { (95\% CI } 0.70-1.09) ; \text { stroke, HR } 1.18 \text { (95\% CI } 0.89- \\
1.56) ; \mathrm{CV} \text { death, HR } 0.62(95 \% \text { CI } 0.49-0.77) ; \mathrm{HF} \\
\text { hospitalisation, HR } 0.65(95 \% \text { CI } 0.50-0.85) .\end{array}$ \\
\hline CANVAS $^{28}$ & Canagliflozin & $\begin{array}{l}\text { Total: } 10142 \\
\text { Drug: } 5795 \\
\text { Placebo: } 4347\end{array}$ & $\begin{array}{l}\text { T2DM and history } \\
\text { of or high risk for } \\
\text { CVD, HbA1c } 7- \\
10.5 \%\end{array}$ & 63 & 2.4 & $\begin{array}{l}\text { Primary outcome, HR } 0.86(95 \% \text { CI } 0.75-0.97) \text {; MI, HR } \\
0.89 \text { ( } 95 \% \text { CI } 0.73-1.09) \text {; stroke, HR } 0.87 \text { (95\% CI } 0.69- \\
1.09) ; \text { CV death, HR } 0.87 \text { ( } 95 \% \text { CI } 0.72-1.06) ; \text { HF } \\
\text { hospitalisation, HR } 0.67(95 \% \text { CI } 0.52-0.87) .\end{array}$ \\
\hline $\begin{array}{l}\text { DECLARE } \\
\text { TIMI 5826 }\end{array}$ & Dapagliflozin & $\begin{array}{l}\text { Total: } 17160 \\
\text { Drug: } 8582 \\
\text { Placebo: } 8578\end{array}$ & $\begin{array}{l}\text { T2DM with and } \\
\text { without history of } \\
\text { CVD, HbA1c 6.5- } \\
12 \%\end{array}$ & 64 & 4.2 & $\begin{array}{l}\text { Primary outcome, HR } 0.93 \text { ( } 95 \% \text { CI } 0.84-1.03) \text {; MI, HR } \\
0.89 \text { ( } 95 \% \text { CI } 0.77-1.01) \text {; stroke, HR } 1.01 \text { (95\% CI } 0.84-\text { - } \\
1.21) \text {; CV death, HR } 0.98 \text { ( } 95 \% \text { CI } 0.82-1.17) ; \mathrm{HF} \\
\text { hospitalisation, HR } 0.73(95 \% \text { CI } 0.61-0.88) .\end{array}$ \\
\hline
\end{tabular}

Table 3. Cardiovascular Outcomes Trials of Sodium Glucose Co-transporter 2 Inhibitors. Abbreviations: T2DM=type 2 diabetes mellitus; $\mathrm{HR}=$ hazard ratio; $\mathrm{CI}=$ confidence interval; $\mathrm{MI}=$ myocardial infarction; $\mathrm{CVD}=$ cardiovascular disease; $\mathrm{CV}=$ cardiovascular; $\mathrm{HF}=$ heart failure. 


\begin{tabular}{|c|c|c|c|c|c|c|}
\hline Drug & Dose & Dose interval & HbA1c (\%) & Weight (kg) & $\begin{array}{l}\text { Systolic BP } \\
\text { (mmHg) }\end{array}$ & Renal dosing \\
\hline Empagliflozin & $10-25 \mathrm{mg}$ & Once daily & $-0.69(-0.81,-0.56)$ & $\begin{array}{l}-2.04(-2.31,- \\
1.77)\end{array}$ & $\begin{array}{l}-2.59(-2.70,- \\
2.49)\end{array}$ & $\begin{array}{l}\text { Contraindicated if } \\
\text { eGFR }<30\end{array}$ \\
\hline Canagliflozin & $100-300 \mathrm{mg}$ & Once daily & $-0.88(-1.03,-0.72)$ & $\begin{array}{l}-2.80(-3.21,- \\
2.39)\end{array}$ & $\begin{array}{l}-2.23(-2.28,- \\
2.18)\end{array}$ & $\begin{array}{l}\text { 100mg daily if eGFR } \\
45-59 \text {, avoid if } \\
\text { eGFR }<45\end{array}$ \\
\hline Dapagliflozin & $10 \mathrm{mg}$ & Once daily & $-0.61(-0.70,-0.52)$ & $\begin{array}{l}-2.13(-2.45,- \\
1.82)\end{array}$ & $\begin{array}{l}-1.03(-1.09,- \\
0.97)\end{array}$ & Avoid if eGFR $<60$ \\
\hline
\end{tabular}

Table 4. Effects of Sodium Gilucose Co-transporter 2 Inhibitors on HbA1c, Weight and Systolic Blood Pressure. Values shown are for maximum daily doses versus placebo 3445 47. Abbreviations: BP=blood pressure, eGFR=estimated glomerular filtration rate. 


\section{Figure legends}

Figure 1. Mechanisms of action, main effects and cardiovascular benefits of glucagon-like peptide 1 receptor agonists and sodium glucose co-transporter 2 inhibitors. Abbreviations: SGLT2i=sodium glucose co-transporter 2 inhibitor; GLP1ra=glucagon-like peptide 1 receptor agonist; ASCVD=atherosclerotic cardiovascular disease; $\mathrm{HF}=$ heart failure.

Figure 2. Considerations for selecting second-line glucose lowering drug in cardiology patients with type 2 diabetes mellitus. Abbreviations: SGLT2i=sodium glucose co-transporter 2 inhibitor; GLP1ra=glucagon-like

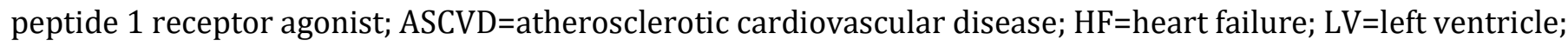
eGFR=estimated glomerular filtration rate. 